\title{
Is Science Rational: Critical Analysis on Thomas Kuhn's Objectivity, Value Judgment and Theory Choice and Harvey Siegel's Inquiry Concerning the Rationality of Science
}

\author{
Abdeta Mamo Hiko \\ Department of Civics and Ethical Studies, Madda Walabu University, Bale, Robe, Ethiopia \\ Email address: \\ abdetamamo@gmail.com \\ To cite this article: \\ Abdeta Mamo Hiko. Is Science Rational: Critical Analysis on Thomas Kuhn's Objectivity, Value Judgment and Theory Choice and Harvey \\ Siegel's Inquiry Concerning the Rationality of Science. International Journal of Philosophy. Vol. 8, No. 3, 2020, pp. 61-67. \\ doi: 10.11648/j.ijp.20200803.11
}

Received: May 27, 2020; Accepted: June 22, 2020; Published: July 30, 2020

\begin{abstract}
Is science rational is the central concern of this paper. The paper mainly examines the wisdom of science based on Thomas Kuhn objectivity, value judgment and theory choice and Harvey Siegel's examination about the rationality of science. In doing so for Kuhn, the central argument of scientific rationality is reasonableness and logicality in justification and to be reasonable and logically justifiable for what we do. What ensures that science is rational is the dedication to evidence. It also explores Siegel's concept of scientific method and his justification of the received view of science. Thus, I employed philosophical method of analysis and phenomenology. This paper maintains that choosing rational activity of our reason for the rival theories is not determined by universal standard. I thus, suggested that his rationality of science as lack of objective reasons for why scientists should favour one theory over another. Instead, my main argument Kuhn rationality of science in his five criterion of theory choice is imprecise. Because, this standard restrict one's which is theory choices are not sufficient to persuade or clearly to confirm the choice of one paradigm over the other. Thus, I deffend the position that no rational justification outside paradigm and I argues, against a kind of rationality with which science should be identified and proceeds in agreement.
\end{abstract}

Keywords: Science, Rationality of Science, Theory Choice, Objectivity, Value Judgment, Scientific Method

\section{Introduction}

In this paper, I will explore the rationality of science based on Thomas Kuhn's “Objectivity, Value Judgment and Theory Choice" and Harvey Siegel's "What Is the Question Concerning the Rationality of Science". From the very beginning, philosophy has been very influential for science, as has science been for philosophy [1]. For the nature of work expected in this paper, it seems most appropriate, reasonable and logical to begin with a working definition of science. This may not be a simple task knowing that there is no standard definition of the term "science". So, instead of looking for a definition of science, I believe it is most appropriate to look at different conceptions of science.

Accordingly, the term science means knowledge arranged in an organized manner, especially knowledge derived from experience, observation, and experimentation [2]. This is the reason why science often claimed that scientific knowledge is proven knowledge. Science is thus based on what we can see, touch taste, hear or smell. Consistently, what this means is that personal opinions, prejudices or preferences, superstitious and speculative imaginations have no place in science [ibid].

When I was postgraduate students of philosophy I attend the course philosophy of Science and Technology, I faced uncertainty about rationality of science. So, this why I raised a question for my professor Dr Setergew Kenew "Is a science rational? Accordingly, my professor inspired me to write a short term paper on this area to come out of the uncertainty. This was a time that I started to find the way through my puzzlement.

This topic, is science rational, discusses Kuhn's theory choice and Siegel's explanation of the scientific method with respect to the rationality of science. With Kuhn, we see how he challenges the received view of science and how he shows the possibility of having a new reflection of science through his discussion of theory choice. 
The paper briefly discusses Kuhn's theory choice in relation to the rationality of science and Siegel's concept of scientific method and his justification of the received view of science.

Broadly, after critically examining the points that will be raised in the philosophy of Kuhn theory choice and Siegel rationality of science, the paper takes Kuhn's position and argues that theory choice is not a completely rational decision and that this does not necessarily imply that science in general or theory choice in particular is irrational. Also, it tries to show that Siegel's account of scientific rationality that it consists in the Scientific Method (SM) is not adequate as he thinks. Finally, this paper argues against kind of rationality with which science should be identified and proceeds in agreement. Besides, I will conclude the paper giving my own position of rationality of science.

Accordingly, this paper has four major parts. The first one is introductory part. The second section deals with the body of the paper which concerns brief analysis of the central theme of the above topic. Whereas the third part, emphasize my own critical reflection on the central argument of the given topic. Finally, the fourth part concerns with the conclusion of the paper.

\section{Discussion}

\subsection{Thomas Kuhn Theory Choice ${ }^{1}$}

Regarding the question of rationality of science, many philosophers of science have asked the question whether or not science is rational; and if it is rational where its rationality lies. They tried to challenge the received view of science that it is rational, objective, disinterested, reliable, methodological, and so on. Some deprived of science its claim of rationality while others tried to put its rationality in sciences method or objectivity and there are some others who tried to give different account of its rationality. However, first, what is the term rationality is?

According to a traditional philosophical outlook, dating back to Aristotle and shared by Immanuel Kant and many others, what makes human beings different from the other animals is that human beings are "rational" or have "reason." The validity of this claim depends, of course, on what it is taken to mean. Both informally and in academia, the terms "reason" and "rational" are used in many different ways. "Reason" may be used to denote sanity, as when people say that a mentally deranged person has "lost his reason." "Rational" may be used to mean arranged and intelligible, or in accordance with causal laws, as when people say they believe that the world is a "rational place." "Reasoning" may be taken to explain the activity of working out what to do or believe by thinking, in which case "reason" is simply the capacity to do that [3].

In line with this point Immanuel Kant held that rational beings as "persons" are "ends in themselves," while non-rational animals are "things" which may legitimately be

1This part is based on an article by: Thomas Kuhn [2] "Objectivity, Value Jugment and Theory Choice" in Marc Lange (ed.), Philosophy of Science; An Anthology, Blackwell Publishing. From page (356-367) used as mere means to the ends of rational beings. Many writers in the philosophical literature assume that what Kant meant is simply that rationality has a kind of intrinsic value which in turn confers value on those who have it [13].

I think, rationality means reasonableness, wisdom, or prudence. In his book "Progress and its Problems", Larry Laudan defines rationality as follows:

At its core rationality consists in doing (or believing) things because we have good reasons for doing so... if we are going to determine whether a given action or belief is (or was) rational we must ask whether there are (or were) sound reasons for it [9]

The above quotation shows that rationality means to have a sound reason for whatever you are saying or doing, or for whatever goal you are following. However, one can still ask whether it is the belief or the action to be held that must be rational in and of itself or there as on why we hold the belief. Because sometimes you may hold an irrational belief for a very sound reason; and/or you may hold a rational belief for an unsound reason.

Indeed, rationality requires reasoning strategies that are effective for achieves goals, so discussion of the rationality of science must consider what science is supposed to accomplish [1]. Science is rational to the extent that the beliefs that it accumulates are true, and scientific reasoning is rational to the extent that it tends to produce true beliefs.[3] In addition to this. Duesk argues that science sees themselves as advocates of the rule of reason and they understand reason to mean scientific reason [4]. This shows that there is compatibility between science and rationality.

Indeed, to address of rationality of science in Kuhn is to address of Kuhn's conception of theory choice. ${ }^{2}$ In Kuhn scientific revolution anomalies guide to revolution which affects a new competitor paradigm that in turn puts the scientists in the old paradigm into the dilemma of choice. New paradigm emerges when it is able to solve the puzzle that resisted solution within the previously honored paradigm. This makes the scientists working in that paradigm lose their confidence in it and then come to the need to choose between the newly emerging and the formerly held paradigm, this situation is called dilemma of choice [6]. How does a scientist choose between two paradigms? On the other hand, how does he/she abandon a one time-honored theory or paradigm in favor of another? Kuhn explains this dilemma when as follows:

In the pen ultimate chapter of a controversial book first published fifteen years ago, I considered the ways scientists are brought to abandon onetime-honored theory or paradigm in favor of another. Such decision problems, as I wrote, cannot be resolved by proof. To discuss their mechanism is, therefore, to talk about techniques of persuasion or about argument and counter argument in a situation in which there can be no proof

2The concept theory choice is important to understand Kuhn notion rationality of science. Because Kuhn in his postscript he change his ideas that have before about the rationality of science. Without the concept of theory choice, it is difficult to understand Kuhn rationality of science. On the other hand, theory choice is the base for rationality of science for Kuhn. 
[Ibid].

What is understandable from the above expression is that, it is so reasonable for one to expect that there is a binding reason or criterion, which dictates the theory choice of each individual if one accepts the traditional received view of science. If what traditional thinkers believe is true about science, then there must be rationally grounded standards that can bind everyone's choice of theory. This standard must be logical, rational, objective and binding. Kuhn challenges this conception of theory choice that theory choice is a "completely rational" decision (ibid).

Kuhn in his post script starts by asking a question: What are the characteristics of a good scientific theory? Or what are the values" for judging scientific theories? Kuhn himself answers this question by mentioning five characteristics. These are accuracy, consistency, scope, simplicity and fruitfulness. [6]. According, to Kuhn, these characteristics are standard criteria for evaluating adequacy of a scientific theory. Collectively with others of much the same sort, they provide the shared basis for theory choice. However, he recommended "Individually the criteria are imprecise: individuals may legitimately differ about their application to concrete cases" (Ibid). This is to mean that there is reasonable subjective judgment in objective criteria enlisted above because they are imprecise individually or there are variations in them. For example, simplicity of theory does not indicate its simplicity for all [ibid]

Kuhn considered these criteria as values that are secure (with their character of variations and imprecision) whatever transitions will come. For this reason, the above methodological rules and standards do restrict one's theory choices, they are not sufficient to persuade or clearly to certify the choice of one paradigm over the other. Hence, since there is disagreement on theory-choice at the outcome of paradigm shift, there is no set of rules or criteria that help us to rationally induce proponents of the old paradigm to throw away the old paradigm in favor of the new one and vice versa. Kuhn thus argued that "... the choices scientist make between competing theories depend not only on shared criteria- those critics call objective- but also on idiosyncratic factors dependent on individual biography and personality"[Ibid]. From the above explanations we can realize that Kuhn is not methodological relativist.

Moreover, when scientist must choose between competing theories, two men/women fully committed to the same list of criteria for choice may nevertheless reach different conclusions. This might happen because they interpret the criteria differently or have different beliefs about the range of fields with in which a particular criterion must be met. Possibly, this is not a profound problem that causes the difficulties, because scientists may define a particular criterion in a particular way for their own purposes, which would be used alike by every scientist operating within that system. I think, the real problem is the problem Kuhn mentioned next is the problem of weight. Perhaps, Kuhn says, they agree about the matters of definition and conviction but differ on the relative weights to be deals to these or to other criteria when several criterions are used together.

I think, the problem of weight is a real problem to apply the criteria when one must choose between two competing theories. Different people may deal with different weight to different criteria. Divergence of this sort is unavoidable, for it depends up on personal characteristics of the individual making a choice. Every scientist may not, or even definitely not, accord the same weight to a particular criterion of choice. Even if this is possible, that every scientists accord the same weight to one particular criterion, that particular criterion alone cannot be sufficient to make a rational theory choice. There must be other criteria used to get her with that particular criterion about whose weight every scientists agrees. Now, I can say that every scientist does not have same personality and world view, and hence cannot accord the same weight to every criterion, for the weight we accord to criteria depend sponsor personal characteristics, and worldview. For such kind of divergence is inevitable, no set of choice criteria possibly proposed could be sufficient by themselves.

Moreover, some of the differences I have in mind, Kuhn says, result from the individual's earlier experience as a scientist. In what part of the field, Kuhn asks, was he/she working when confronted by the need to choose? How long had he/she worked there; how successful had been and how much of his/her work depended on concept and techniques challenged by the new theory? The answer to these questions lies beyond science. This implies that other factors relevant to choice recline outside the sciences. Kuhn further elaborates such competing theories as follows:

My point is, then, that every individual choice between competing theories depends on a mixture of objective and subjective factors, or of shared and individual criteria. Since the latter have not ordinarily figured in the philosophy of science, my emphasis upon them had made my belief in the former hard for my critics to see [ibid]. I want to underline on this point a little bit further. Now, Kuhn is not talking about "irrationality of science in general", nor is he claiming that theory choice is "completely irrational". What he is saying, however, is that there is an aspect of irrationality in every individual choice one makes between two competing theories. He does not say that theory choice is a completely subjective act; but rather he states that there is a subjective element that is absorbed within the objective criteria that any individual cannot ignore during theory choice. I, slightly, agree with Kuhn regarding this point: the point that every individual choice between competing theories depends on mixture of objective and subjective factors or of shared values and individual criteria. Kuhn is not denying that there are some shared objective criteria but he is telling us that one cannot choose between two competing theories depending upon these shared values. Man/women cannot put aside all of him/herself and make a completely neutral choice based upon the shared criteria. Explicitly or implicitly, some subjective personal factors will affect his/her choice. 


\subsection{Harvey Siegel}

What Is the Question Concerning the Rationality of Science $^{3}$ ?

In Thomas Kuhn philosophy of science, we have seen the critical evaluation rationality of science exists in theory choice and the central theme of scientific rationality is reasonableness and logicality in justification. Now let us turn our consideration to one of the great philosophers of science that, in fact, defends and supports the received view of scienceHarvey Siegel. Siegel provides defense for the traditional received view of science and the rationality of science. Below we shall see his views about rationality of science and scientific method as he writes in a journal article entitled, "what is the Question Concerning the Rationality of Science?"In this paper, Siegel defends the traditional view of science. He starts the paper by quoting Bertrand Russell in "A History of Western Philosophy":

It is not what the man of science believes that distinguishes him, but how and why he believes it. His beliefs are tentative, not dogmatic; they are based on evidences not on authority and intuition [8].

Here what Russell mentioned in the above formulation is that Siegel explains and suggests two traditional and related beliefs about science. The first is that there is a particular way in which a scientist goes about validating a scientific belief; that way, which is the hallmark of scientific activity, is the scientific method. The second is that the method legitimates scientific activity, and justifies scientific inquiry; that is, science is a rational activity, and that its rationality is secured by the scientific method. Even though these two beliefs have been taken for granted until recently, scientists, lay persons, and some contemporary philosophers of science challenge both idea claiming that there is no such thing as the scientific method and that science is not best seen as rational or, that its rationality is not function of its method (ibid:518).

In his paper, Siegel tries to defend the traditional beliefs against these recent challenges. He argues that the validity of these challenges rests on confusion between different questions one might ask about science's rationality. He also suggests that once these questions are sorts out, the puzzles that have mystified philosophers working in this area in part easily solved, or at least the requirements for their solutions become clearer.

The traditional view of science assumes that rationality of science is a function of its method. Siegel defends this view against those philosophers who either, try to locate science's rationality elsewhere or who reject rationality of science. Here Siegel quotes Hempel:

In so far as a proposed methodological theory of science is to afford an account of scientific inquiry as a rational pursuit, it will have to specific certain goals of scientific inquiry as well as some methodological principles observed in their pursuit: finally it will have to exhibit the

3 This is based on Siegel, H. (1985) "What Is the Question Concerning the Rationality of Science" in Philosophy of Science. JSTOR: Vol. 52, No. 4.University of Chicago Press. From page (517-537) instrumental rationality of the principles in relation to the goals. Only to the extent that this can be done does the conception of science as the exemplar of rationality appear to be variable [9]

The above quotation indicates that Hempel's account of rationality of science relies heavily on a determination of the goals of scientific inquiry. However, Siegel does not accept such instrumental or "means-ends" rationality. Siegel does not accept such instrumental rationality by asking the rationality of the goal a given scientific inquiry is pursuing. Concerning the instrumental view, Siegel believes science rational if its procedure and methodological norms are instrumentally successful in achieving its goals. But this raises another issue: the issue of the goal of science.

Siegel, I think, is telling us that in "means-ends" rationality, we have to evaluate the rationality of the goals we are acting to achieve as well as the means. No matter how rational the means would be, if the goal were itself an irrational goal, so much for the means. The point, claims Siegel, is that the rationality of activity, which is means to some end, depends not only on the instrumental efficacy of the means with respect to the end, but on the rationality of the ends as well. Thus, if we act efficaciously with respect to some irrational end, our actions, though instrumentally efficacious, are not rational. Scientific inquiry, therefore, concerns not only scientific activities, like that of Hemple's, but also the fruits of such inquiry-that is, of the rational justifiability of the claims, hypothesis, and theories which are the results of scientific inquiry. That is, an account of the rationality of science should address the rationality of scientific belief, as well as the rationality of scientific inquiry.

After all, continues Sigel, the question concerning the rationality of science arises because of confusion among the following three questions. [ibid]

Q1) In what does the rationality of science consist?

Q2) What is to count as evidence, or good reason, for some scientific hypothesis or procedure?

Q3) Is actual science (contemporary or historical) rational?

Q1 calls for definitions or explication of the concept of rationality as that concept applies to science. It calls for clarification of the meaning of the attribution of rationality (irrationality) to science.(ibid). I believe that this question must be answer first before we talk of the rationality of science. If we are not clear with the concept of rationality within the arena of science, we can never be able to answer the question of the rationality of science. Nevertheless, this does not mean that the answer to Q1 solves the problem of the rationality of science; instead, it just paves the way.

Q2, Sigel claims, by contrast, asks a different question. It presupposes that the answer to Q1 grounds science's rationality in a commitment to evidence, and then goes on to enquire about the constitution of evidence in science.

Q3, for Siegel this is an empirical question, which only detailed empirical investigation can settle. We should not expect a unitary answer to it, in any case, some episodes of actual scientific activity and belief will no doubt turn out upon investigation to be rational, others not. Moreover, he claims 
that Q3 should not be answered by an answer to Q1 although he does not claim he answered Q2 and Q3, he says his account answers Q1.

But I do not think his account fully answers Q1. In Q1, when he explains, he says that Q1 asks for the definition and explication of the concept of rationality as it applies in the field of science. But he only answer to the latter question that the rationality of science lies in its method, that we shall discuss in the next section, leaving the question about and explication of the concept. According to Siegel, the rationality of science lies in its method-the scientific method. He explains scientific method (SM) as:

The hallmark of SM is its commitment to the establishment of the epistemic worth of scientific claims by virtue of the establishment of the evidential support of those claims. It is in this sense that scientific method is best characterized generally, in terms of commitment to evidence, rather than in terms of specific views regarding the unpacking of particular methodological criteria [8].

Many philosophers of science have been criticizing "the SM"4 claiming that there is no single method sciences employ, i.e. there is no specific method, which all scientists use or ought to use. Siegel acknowledges that scientists do many different arranges of things when engaged in scientific activity: they classify, observe, deduce, generalize, hypothesize, evaluate, etc. In turn, each of this can be done in various ways. For instance, the way an astronomer observes is quite different from the way a biochemist, anthropologist, or particle physicist might do. Given the variety of activities, which make up scientific inquiry, and the variety of ways that these several activities can behaved, it seems, Siegel says, mistaken to hold to the existence of a unique method of science.

Moreover, Siegel claims that some philosophers' rejection that characterization of a unique SM cannot arise from their failure to understand the difference between methods and techniques. The procedures scientists use while observing, classifying, deducing, etc can best taken to be techniques, not methods. There is, Siegel insists, no procedure that is constitutive of SM or that ensures that science is rational. What ensures that science is rational is the commitment to evidence or, better; science is rational to the extent that it proceeds in accordance with such a commitment. Therefore, the only thing that is takes to be the SM must be science or scientists' commitment to evidence. Siegel further strengthens this point when he writes:

Characteristics taken to reflect key features of science-non dogmatism, self-correction, and the like are direct consequences of the commitment to evidence. While methods and procedures for doing science change, the commitment to evidence is basic and essential If this changed or was given up, then we would have to regard the new activity as something other than science [ibid].

The above quote shows that Siegel thinks this kind of

\footnotetext{
${ }^{4} \mathrm{SM}$ means in this paper scientific method is tools which generate logic of justification. It provides evidence to the extent that tends to produce true beliefs. This special tool is expected to aid scientists in the discovery of new theories.
}

rationality of science solves most of the problems philosophers of science have been fighting with for so long; or at least makes it simple to render it a solution. However, I think, it is still problematic to assert, as Siegel does, that science's rationality lies in it is method; and SM is simply science's commitment to evidence. I explain this point in the critical reflection part of Siegel rationality of science.

\section{Critical Reflection}

As it can be seen from the forgoing discussion, there are some points I disagree with in Kuhn's theory choice, Siegel scientific method and there are some points I agree to some extent. There is a point I want to explain because it is mistaken to some extent. Accordingly, Kuhn's theory choice has been mistaken in some respects. Some, of them for example, think that Kuhn considers the entire of science as irrational activity; others think that Kuhn submits theory choice as irrational activity, and some others believe that Kuhn is relativist on the subject of theory choice. Conversely, my sympathetic of Kuhn is different from all these. Kuhn has not said the completely scientific enterprise is irrational; and that theory choice is a "completely irrational" action. What I comprehend of Kuhn's theory choice is that he wants to tell us that our strong belief in the received view of science is naïve. I slightly interpret his theory choice as in part rational action that has an irrational aspect in it.

Kuhn does not clearly tell us the existence of unreasonable element in theory choice. I think with the intention of the existence of unreasonable element in theory choice is completely wrong to look forward scientist, who is human being with different condition of life like history, belief, reason, culture, religion and etc. Every choice of man makes relates to and affected by these conditions of human life. A man not outside of his experiences, belief, his emotions, his expectations and his worldview and just make a decision or choice using his rationality alone. We can quiet our emotions or beliefs for some time, but we cannot abandon them out entirely. A scientist is no different from this. His, scientist's, expectations, emotions, worldview, beliefs etc. besides to the so-called rational and objective criteria of choice, affects and shapes the choice he makes.

I strongly agree with Kuhn's notion of incommensurability between two rival paradigms with regard to rationality of science. This is the point on which many thinkers incorrectly criticized Kuhn. In the process of theory choice, we can compare theories in various ways. For example, we can compare competing theories to understand what is lost when a new paradigm succeeds out over the old one, which theory solved rigid problems, which one of them was successful in their predictions, and so on. As I try to expose it out, for Kuhn, objective criteria such as accuracy, simplicity, scope and the like only guide. However, not dictate theory choice for the fact that they are imprecise, contradict each other in certain situations, open to reasonable personal judgments and so forth, and individual proponents of rival paradigms can disagree in a situation of theory evaluation without any of them being 
irrational. He is correct because rational disagreement itself unquestionably implies rationality of science. In other word, one might argue that there is evidence that people are confirmation agents and not very good ones in that they tend towards confirmation bias in looking excessively to confirm their hypotheses rather than falsify them [14]. Yet, the psychological experiments that find confirmation biases involve reasoning tasks that are much simpler than those performed by actual scientists.

In addition, he also claims that the nature of our judgment regarding the choice of rival paradigms is determined more or less by the practices of the relevant organized scientific community rather than by set of rules or standards [5]. In my opinion, this does not imply subjectivity or irrationality of science. Isn't such choosing is rational activity, even if our reasons to choose one of the rival theories is not determined by universal standard or set of rule? Completely it is. This notion of theory choice is indeed based on good reason rather than on mere mob psychology.

A person who rejects one theory in goodwill of the other has reasons and the procedure of choosing that theory is not a matter of experience but a matter of reasonable argument and counter argument [13]. This does entail neither epistemological relativism nor subjectivism. To choose one theory over another, not only objective qualities of that theory, but also its ability to solve problems, its success in predictions, personal distinctive factors which are grounded on competitor's character play a significant role in the matter of theory choice. This is what many of his critics failed to recognize.

Having saying so about my own critical reflection on Kuhn's theory choice, in relation with the rationality of science now let us turn to my own critical reflection to Siegel's scientific method as the point of reference for the question in the rationality of science. For Siegel no procedure that is constitutive of scientific method or that ensures that science is rational. What ensures that science is rational is the commitment to evidence or, better; science is rational to the extent that it proceeds in accordance with such a commitment. Siegel thinks this kind of rationality of science solves most of the problems philosophers of science have been fighting with for so long; or at least makes it simple to render it a solution.

However, I think, it is still problematic to assert, as Siegel does, that science's rationality lies in it is method; and scientific method is simply science's commitment to evidence. One can ask different question regarding such hypothesis. Let me now pose question to Siegel: Does a method a particular enterprise uses alone make the enterprise itself a rational enterprise? Is it possible for an irrational enterprise to use a rational methodology, which it might not justify? I even do not agree with the whole idea that "the rationality that philosophers of science have been looking for in science" lies in its methodology. Because it is possible for an irrational enterprise to sometimes use a rational methodology, and sometimes a rational enterprise could possibly employ an irrational methodology [16].

In line with this point most scientists talk and act as if they are trying to figure out how the world actually works, not just attempting to make perfect predictions. Moreover, the remarkable technological successes of science are completely mysterious unless the scientific theories that made them possible are at least approximately true [13]

The other thing concerns the content and type of the evidence that science is committed too. Let us believe that it is true that "science's rationality consists in its method, and the only SM is sciences' commitment to evidence". However, here, are not we expected to know something about the evidence we are attaching to? Siegel does not say a thing about then a true and contents of the evidence science or a scientist is committed to; he insists that what makes science scientific is its commitment to evidence. The question is what kind of evidence is that evidence? Is it experimental or logical? Is it rational in and of itself simply by virtue of being evidence? What is the criterion of good evidence? What kind of evidence is sufficient claim to holding a particular scientific belief? These are the points he should have considered while proposing his account of the rationality of science. Unless these questions are properly addressed and specified, it is in experienced to think that Siegel's account of rationality of science, solves the problem at hand-the problem of rationality of science. It still fails to defend itself.

\section{Conclusion}

As it has been discusses so far Kuhn and Siegel introduces an articles: "Objectivity, Value Judgment and Theory Choice" and "What Is the Question Concerning the Rationality of Science" respectively on the rationality of science. In this article, Kuhn began with critical evaluation of rationality of science exists in line with theory choice and Siegel believe that rationality of science consists in its method, and the only scientific method is sciences commitment to evidence. In doing so for Kuhn, the central theme of scientific rationality is reasonableness and logicality in justification. We have to be reasonable and logically justifiable for what we do and reasonably and logically justify what we do [17]. Kuhn's perception of scientific rationality is identical with that of $\mathrm{C}$. G. Hempel and Wesley Salmon. However, for Siegel no procedure that is constitutive of scientific method or that ensures that science is rational. What ensures that science is rational is the commitment to evidence or, better; science is rational to the extent that it proceeds in accordance with such a commitment. He thinks this kind of rationality of science solves most of the problems philosophers of science have been fighting with for so long; or at least makes it simple to render it a solution.

I have argued that some of the usual claims about Kuhn theory choice. Kuhn theory choice is the conception that is indeed based on good reason rather than on mere mob psychology. For him theory choice is set of beliefs when one theory win over the other theory or paradigm shift from old paradigm to the new paradigm. In doing so, such choosing is rational activity, even if our reason to choose one of the rival theories is not determined by universal standard or set of rules. 
This is why I somehow criticized his rationality of science as lack of objective reasons for why scientists should favour one theory over another.

Instead, my main argument Kuhn rationality of science in his five-criterion of theory choice is imprecise. Because, this standard do restrict one's theory choices, they are not sufficient to persuade or clearly to certify the choice of one paradigm over the other. Thus, no rational justification outside paradigm. If the kind of argument that I claim in this paper is right, then we have enough reasons to think that rationality of science faces some sorts of criticisms. These criticisms bring a set of justification for the objections that they forwarded. Therefore, Kuhn and the opponents' rationality of science have their own views that a belief can or cannot be supported by the other sets of belief for its justification.

\section{References}

[1] Sebastian de H. (2019), Science and Philosophy: A Love-Hate Relationship. Cambridge University Press

[2] Wogu, I. (2016), A Critical Analysis of Karl Popper's Verisimilitude Thesis and the Hallmark of Science. International Journal of Contemporary Applied Sciences Vol. 3, No. 8, August 2016 (ISSN: 2308-1365) www.ijcas.net 14

[3] Thagard, P. (2004). Rationality and science. In A. Mele \& P. Rawlings (Eds.), Handbook of rationality. Oxford: Oxford University Press, (pp. 363-379).

[4] Goldman, A. (1999). Knowledge in a social world. Oxford: Oxford University Press.

[5] Godfrey-Smith, Peter (2003) Theory and Reality: an Introduction to Philosophy of Science, Chicago and London, the University of Chicago Press

[6] Kuhn, T. (1977) “Objectivity, Value Judgment and Theory
Choice" in Marc Lange(ed.), Philosophy of Science; An Anthology. Blackwell Publishing

[7] Kuhn, T. S. (1970) The Structure of Scientific Revolution, 2ndEd, London: Chicago University Press

[8] Salmon. W. (1983) "Carl G. Hempel on the Rationality of Science" The Journal of Philosophy, Vol. 80, No. 10, Part 1: Eightieth Annual Meeting of the American Philosophical Association, Eastern Divisionpp. 555-562

[9] Siegel, H. (1985) "What Is the Question Concerning the Rationality of Science" in Philosophy of Science. JSTOR: Vol. 52, No. 4, PP. 517-537. University of Chicago Press, available on.

[10] Hempel, C. G. (1965). Aspects of scientific explanation. New York: The Free Press

[11] Zamora Bonilla J. P., (2010), “What games do scientists play? Rationality, objectivity, and the social construction of scientific knowledge", EPSA Epistemology and Methodology of Science: Launch of the European Philosophy of Science Association, ed. M. Suárez, Springer, Amsterdam, pp. 323-332.

[12] Dusek, V. (2006) Philosophy of Science and Technology. Black Well Publishing.

[13] Jennifer K. Uleman 2010, An Introduction to Kant's Moral Philosophy. Cambridge University Press

[14] Psillos, S. (1999). Scientific realism: How science tracks the truth. London: Routledge.

[15] Klayman, J., \& Ha, Y. (1987). Confirmation, disconfirmation, and information in hypothesis testing. Psychological Review, 94, 211-228.

[16] Popper, K. (2002) Conjectures and Refutations, (Routledge \& Kegan Paul New York).

[17] Kenaw, Setargew (PhD), (2015) Unpublished Lecture Notes on philosophy of science: Addis Ababa University, Department of Philosophy. 